\title{
Occurrence of the microsporidian parasite Nucleospora salmonis in four species of salmonids from the Massif Central of France
}

\author{
Hicham El Alaoui*, Stéphane J. Grésoviac* and Christian P. Vivarès \\ Equipe de Parasitologie Moléculaire et Cellulaire, LBP, UMR CNRS 6023, Université Blaise Pascal, 63177 Aubière Cedex, \\ France \\ *The first two authors contributed equally to this work
}

Key words: Microsporidia, Nucleospora salmonis, intranuclear parasite, salmonid fish, rDNA

\begin{abstract}
Nucleospora salmonis (Hedrick, Groff et Baxa, 1991), an intranuclear microsporidian parasite of marine and freshwater fish, causes diseases mainly in salmonid species. Losses have been reported in stocks of salmonid fish reared in the region of Auvergne (France). The cause of chronic mortalities in the local host species raised in aquaculture and destined for supplementation of the river system Loire-Allier was examined. The presence of N. salmonis was confirmed by PCR and histology in Salmo salar L. previously and in newly investigated salmonid species, Salmo salar, Salmo trutta fario L., Thymallus thymallus (L.) and Salvelinus alpinus (L.), present in European streams. The infection by N. salmonis was consistent in all cases with characteristic symptoms of the disease in deceased or moribund fish. The small subunit ribosomal DNA from $N$. salmonis was partially sequenced and compared to previously characterised $N$. salmonis isolates. As a result, a genotype, or clonal entity, was attributed to N. salmonis among Atlantic salmon found along the Northern Atlantic coastal lines and other salmonid species co-inhabiting or co-cultivated in the Auvergne region.
\end{abstract}

Microsporidia are obligate intracellular unicellular parasites of all the major animal groups. Several microsporidian genera have been observed in aquatic organisms, including fish. Five species are capable of development in the nucleus of their host cell. Two species are salmonid parasites: Nucleospora salmonis (Hedrick, Groff et Baxa, 1991) in various salmonid species (see below) and Microsporidium rhabdophilia Modin, 1981 in Oncorhynchus sp. Others are in marine and freshwater fishes, respectively Nucleospora sp. of Mullins et al. (1994) in lumpfish, Cyclopterus lumpus L.; Nucleospora sp. of Nilsen et al. (1995) in Atlantic halibut, Hippoglossus hippoglossus (L.); and Nucleospora secunda Lom et Dyková, 2002 in killifish, Nothobranchius rubripinnis Seegers (Lom 2002, Lom and Nilsen 2003). Microsporidium rhabdophilia was not associated with any clinical signs (Modin 1981). In contrast, $\mathrm{Nu}$ cleospora salmonis, formerly known as Enterocytozoon salmonis, was first reported as the cause of chronic losses among populations of Chinook salmon, Oncorhynchus tshawytscha (Walbaum). Hedrick et al. (1990), Morrison et al. (1990), and Chilmonczyk et al. (1991) characterised $N$. salmonis and the resulting symptoms of the disease. Infections in adult or juvenile salmon are usually characterised by severe anaemia and a leukaemic-like state (Antonio and Hedrick 1995). Nucleospora salmonis can affect several cell types but mostly and almost exclusively realises its life cycle in the nuclei of lymphopoietic-like cells, inducing in them an unusual lympho-proliferation. The pathological signs associated with $N$. salmonis infections demonstrate similarities with those reported for plasmacytoid leu- kaemia in Chinook salmon (Kent et al. 1990, Eaton and Kent 1992, Eaton et al. 1994). However, the clinical relationship between the two diseases remains unclear since the primary agent of symptoms could not be determined in co-infection cases. Since the first reports in the American Pacific Northwest region (Eltson et al. 1987, Hedrick et al. 1990, Morrison et al. 1990, Khattra et al. 2000) N. salmonis and N. salmonis-like pathogens have been detected in various states and provinces of the USA and Canada, in Europe (France and Norway), and in South America (Chile) (Mullins et al. 1994, Nilsen et al. 1995, Cubillos et al. 2000), indicating that this microsporidian may be an ubiquist of the waterways inhabited by salmonid fish worldwide. In addition to its global distribution, N. salmonis has been found in numerous species of salmon and trout, including the coho salmon, Oncorhynchus kisutch (Walbaum) (Kent et al. 1995), the rainbow trout, Oncorhynchus mykiss (Walbaum) (Chilmonczyk et al. 1991, MacConnell et al. 1991, Georgiadis et al. 1998), the Atlantic salmon, Salmo salar L. (Kent et al. 1996), the brook trout, Salvelinus fontinalis (Mitchill), and the lake trout, Salvelinus namaycush (Walbaum) (Gresoviac et al. 2000), in freshwater or saltwater environment, in artificially-raised stocks and wild conditions. It is therefore assumed that all salmonid species are potential hosts for N. salmonis (Hedrick et al. 1990, 1991, Gresoviac et al. 2000).

In France, the streams of the Auvergne region host an abundance of fish and are known for the diversity of their salmonid resources. The water systems of that region are historically rich in various salmonids, native or 
imported to that area. This heritage has been recognized for over a century and has made the reputation of this mountain range in the domain of sport fishing and ecological inheritance. Among the different species of salmonids represented in the Massif Central, the Atlantic salmon, S. salar, and more specifically the 'Allier' strain, is a major concern for the industry of tourismrecreation and the environmental organisations. In spite of the reported size of its past runs along the rivers Loire, Allier and their tributaries, at the beginning of the century, this strain of salmon, which included the larger representatives of the species in Europe, is on the verge of becoming extinct. Negative factors comparable to the ones addressed in North America (e.g. water pollution, riverbank modification, dam construction and overfishing, etc.) have progressively diminished the populations of anadromous and resident fish in Auvergne, among which is the threatened 'Allier' salmon. Human influence has rendered unsuitable a large part of the historical habitats and has restricted access to spawning sites. As a consequence, local authorities have recently invested growing efforts in order to restore and preserve the ecosystem of Auvergne, and subsequently the salmon resource in France (hatching and release programs, fishing regulations, dam suppression).

As programs of supplementation and environment measures multiplied to avoid further loss and to ensure the survival of endangered species of salmonid fish, we focus our interest on investigating the prevalence and the impact of the pathology caused by N. salmonis. Because this microsporidian can represent a significant threat not only to farmed fish, but also to all native salmonid species (Hedrick 1997), and because of the economical and ecological stakes involved in the rehabilitation of the 'Allier' salmon, of which only few individuals remain, we examined several potential hosts to assess the risk of outbreaks of the disease in the Massif Central mountain range using histological and molecular tools of detection (Hedrick et al. 1991, Barlough et al. 1995, Wongtavatchai et al. 1995a, Kent et al. 1996, Georgiadis et al. 1998). Our objectives were also to evaluate the repartition of the parasitosis in regards with the formerly formulated hypothesis of ubiquitism (Gresoviac et al. 2000), by inspecting the existence of $N$. salmonis in a landlocked region located within the poorly investigated European continent.

\section{MATERIALS AND METHODS}

Samples. Dead and moribund animals were reported in the rearing ponds of aquaculture facilities located in the Puy-deDôme within the central French region of Auvergne. Six moribund fish showing characteristic signs of the parasitosis were collected from each inspected stock. First hatcherygeneration Atlantic salmons, S. salar L., brown trouts, Salmo trutta fario L., and graylings, Thymallus thymallus (L.), aged between 1.5 and 3 years, were sampled by the local agency of Superior Council of Fishing (CSP) at the hatchery of Au- gerolles established on the Faye river. Additional material was provided by the Veterinary Services of the CSP at the aquaculture of Besse Saint Anastasie, operated on the stream of the Couze Pavin, among 1-2 year old deceased or ill brown trouts and charrs, Salvelinus alpinus (L.).

Histological preparation and DNA extraction were performed from anterior kidney samples from sick individuals demonstrating signs such as anaemic state, uni- or bi-lateral exophthalmos, gill pallor, and swollen intestinal cavity. Additional internal indices, including spleen and kidney enlargement, hyperaemic intestines and excessive fluids in the visceral cavity, were also examined.

We examined wet mounts and genomic DNA from deceased and moribund fish demonstrating characteristic symptoms of the disease (Hedrick et al. 1990, 1991, Morrison et al. 1990, Baxa-Antonio et al. 1992). Tissues and/or imprint slides were sent to the Fish Pathology Laboratory of the University of California at Davis for diagnosis. Wet mounts from suspected infected kidney were fixed in methanol, stained by the May-Grünwald/Giemsa staining (Sigma Biochemical Co., St Louis, Missouri) and examined by direct light microscopy.

Detection by genetic amplification. Genomic DNA from lymphoid tissues from spleen and kidney was prepared with the conventional extraction method employed by Barlough et al. (1995). The collected DNA concentration was estimated by spectrophotometry at wavelengths of 260 and $280 \mathrm{~nm}$. Nested Polymerase Chain Reaction (PCR) assays, based on the small subunit ribosomal DNA (ssu-rDNA), were used to detect $N$. salmonis and partially characterise its genotype. The gene amplication was carried out as described by Gresoviac et al. (2000). The diagnostic primer combinations ES-1/ES-2 followed by ES-3/ES-4 (Gresoviac et al. 2000) and ES-1a/ES-2a followed by ES-3a/ES-4a (Barlough et al. 1995), yielded two distinct amplification products located respectively in the 5 , and 3' regions of the ssu-rDNA. Their combined lengths, of 444 and $405 \mathrm{bp}$, respectively, provided information on $849 \mathrm{bp}$ of the 1275 bp long gene. Supplemental nested PCR reactions were performed using the primer combinations ES-A/ES-B followed by ES-C/ES-D, or ES-A/ES-E followed by ES-C/ES$\mathrm{G}$ (Gresoviac et al. 2000), in order to amplify 1224 or 1187 bp, respectively, of the ssu-rDNA. The PCR products were visualised by standard electrophoresis on $1 \%$ agarose gels.

Cloning and sequencing. The PCR products were cloned and sequenced using procedures described earlier (Gresoviac et al. 2000). Six clones representative of each isolate were sequenced using flanking primers (T7 and M13R) located on the vector. The reactions were accomplished with automatic sequencing kits (Perkin-Elmer/ABI, Foster City, California; Amersham Life Science, Cleveland, Ohio) following the companies' recommendations. The results were analysed with the ABI Prism sequencing 2.1.1 software (Perkin-Elmer/ABI). Resulting rDNA sequences were assembled, aligned and compared to previously characterised N. salmonis genotypes (Barlough et al. 1995, Docker et al. 1997, Gresoviac et al. 2000), using the program Sequencher version 3.0 (Gene Codes Corp., Ann Harbor, Michigan).

Genetic distances and phylogenetic tree. The calculations of genetic distances were made by Clustal_w and EDTALN program (http://www.ebi.ac.uk/clustalw/). 
The program NEIGHBOR tree maker was used for phylogenetic analysis (http://hiv-web.lanl.gov/content/hiv-db/ CONTAM/TreeMaker/TreeMaker.html).

Appendix 1, the alignment of Nucleospora salmonis sequences, can be found on the laboratory web site: http://www. protistes.univ-bpclermont.fr/fr/E-Parasito/frameset_parasito. htm

\section{RESULTS}

The microscopic examination of stained wet mounts of pronephros tissue from fish suspected to be infected by $N$. salmonis and the screening of this tissue by sensitive molecular method indicated that most of the samples originating from Auvergne were infected by the microsporidian. In a large majority of the cases, the signs of the disease were noted and the presence of $N$. salmonis was observed by direct morphological identification during microscopical examination. Given that it is difficult to conclude, we confirmed later the infection in these samples by PCR. Thus, the clinical signs observed among the collected moribund fish were most likely the consequence of the proliferation of $N$. salmonis. Although clinical signs are not systematically associated with the presence of $N$. salmonis, its detection by histology or PCR (Table 1) was consistent with morphological signs of the disease.
Based on 405 and 444 bp fragments amplified by diagnostic primers, we were successful in identifying two-third the ssu-rDNA sequence. The molecular detection of $N$. salmonis rDNA in diseased fish comforted in most cases our initial diagnosis based on clinical signs and microscopic examination. The identification of rDNA sequences permitted a partial characterisation of local genotypes of the parasite. In addition to the afore-mentioned diagnostic primers, we used primers located on the flanking regions of the ssurRNA gene and specifically designed to amplify most of its sequence, in order to further characterise the genotypes of $N$. salmonis from Auvergne. However, we were unable to produce detectable PCR products matching the entire ssu-rDNA. The sequences from Auvergne isolates have been deposited in GenBank under the following accession numbers: DQ 158898: 5 'region of the Nucleospora salmonis ssu-rDNA from Salmo trutta fario; DQ 158899: 3'region of the $N$. salmonis ssu-rDNA from $S$. trutta fario; DQ 158900: 5 'region of the $N$. salmonis ssu-rDNA from Salvelinus alpinus; DQ 158901: 3'region of the N. salmonis ssurDNA from $S$. alpinus; DQ 158902: 5'region of the $N$. salmonis ssu-rDNA from Salmo salar; DQ 158903: 3 'region of the $N$. salmonis ssu-rDNA from $S$. salar.

The genotypes from Auvergne isolates were very similar to the majority of the previously identified

Table 1. Percentage of sick/moribund Auvergne-originating salmonids by species and sites of collection diagnosed with Nucleospora salmonis infection using Giemsa staining and nested PCR assay.

\begin{tabular}{|l|l|l|r|r|}
\hline \multirow{2}{*}{ Species } & \multicolumn{1}{|c|}{ Site } & \multicolumn{3}{c|}{$\%$ (No.) of N. salmonis-infected fish } \\
& & Clinical signs & Wet mounts & PCR \\
\hline Salmo salar $(\mathrm{n}=6)$ & Augerolles (CSP) & $100(6)$ & $83(5)$ & $100(6)$ \\
Thymallus thymallus $(\mathrm{n}=5)$ & Augerolles (CSP) & $100(5)$ & $60(3)$ & $100(5)$ \\
Salmo trutta fario $(\mathrm{n}=4)$ & Augerolles (CSP) & $100(4)$ & $100(4)$ & $100(4)$ \\
Salvelinus alpinus $(\mathrm{n}=12)$ & Besse S $^{\mathrm{t}}$ Anastasie & $100(12)$ & $25(3)$ & $75(9)$ \\
Salmo trutta fario $(\mathrm{n}=4)$ & ${\text { Besse S } \mathrm{S}^{\mathrm{t}} \text { Anastasie }}^{\mid}$ & $100(4)$ & $25(1)$ & $50(2)$ \\
\hline
\end{tabular}

Table 2. Genetic distance matrix calculated by comparison of partial small subunit rDNA sequence data from Auvergneoriginating and previously known Nucleospora salmonis strains.*

\begin{tabular}{|c|cccccccccccc|}
\hline & 1 & 2 & 3 & 4 & 5 & 6 & 7 & 8 & 9 & 10 & 11 & 12 \\
\hline 1 & & 0.6 & 30.5 & 30.7 & 16.4 & 0.1 & 5.3 & 30.7 & 4.2 & 3.3 & 3.3 & 4.6 \\
2 & 0.6 & & 30.8 & 30.9 & 16.9 & 0.5 & 5.8 & 30.9 & 4.5 & 3.5 & 3.6 & 5.2 \\
3 & 30.5 & 30.8 & & 0.2 & 18.6 & 30.5 & 27.6 & 0.2 & 33.3 & 32.9 & 32.9 & 30.5 \\
4 & 30.7 & 30.9 & 0.2 & & 18.8 & 30.7 & 27.7 & 0.2 & 33.5 & 33.1 & 33.1 & 30.5 \\
5 & 16.4 & 16.9 & 18.6 & 18.8 & & 16.5 & 12.9 & 18.8 & 19.9 & 19.2 & 19.2 & 16.3 \\
6 & 0.1 & 0.5 & 30.5 & 30.7 & 16.5 & & 5.3 & 30.7 & 4.1 & 3.2 & 3.2 & 4.7 \\
7 & 5.3 & 5.8 & 27.6 & 27.7 & 12.9 & 5.3 & & 27.7 & 9.1 & 8.3 & 7.3 & 9.0 \\
8 & 30.7 & 30.9 & 0.2 & 0.2 & 18.8 & 30.7 & 27.7 & & 33.5 & 33.1 & 33.1 & 30.5 \\
9 & 4.2 & 4.5 & 33.3 & 33.5 & 19.9 & 4.1 & 9.1 & 33.5 & & 2.1 & 2.4 & 6.2 \\
10 & 3.3 & 3.5 & 32.9 & 33.1 & 19.2 & 3.2 & 8.3 & 33.1 & 2.1 & & 1.3 & 5.3 \\
11 & 3.3 & 3.6 & 32.9 & 33.1 & 19.2 & 3.2 & 7.3 & 33.1 & 2.4 & 1.3 & & 5.4 \\
12 & 4.6 & 5.2 & 30.5 & 30.5 & 16.3 & 4.7 & 9.0 & 30.5 & 6.2 & 5.3 & 5.4 & \\
\hline
\end{tabular}

*1: AF185991 Salmo salar (Atlantic salmon), Chile; 2: AF186003 S. salar, Chile; 3: Salmo trutta fario (brown trout), Auvergne; 4: Salvelinus alpinus (charr), Auvergne; 5: AF186002 S. salar, Chile; 6: AF185990 S. salar, Chile; 7: AF185994 Oncorhynchus mykiss (rainbow trout), France; 8: S. salar, Auvergne; 9: AF185996 S. salar, Canada; 10: AF185987 Oncorhynchus tshawytscha (Chinook salmon), USA; 11: AF185993 S. salar, Chile; 12: AF186000 S. salar, Chile. 


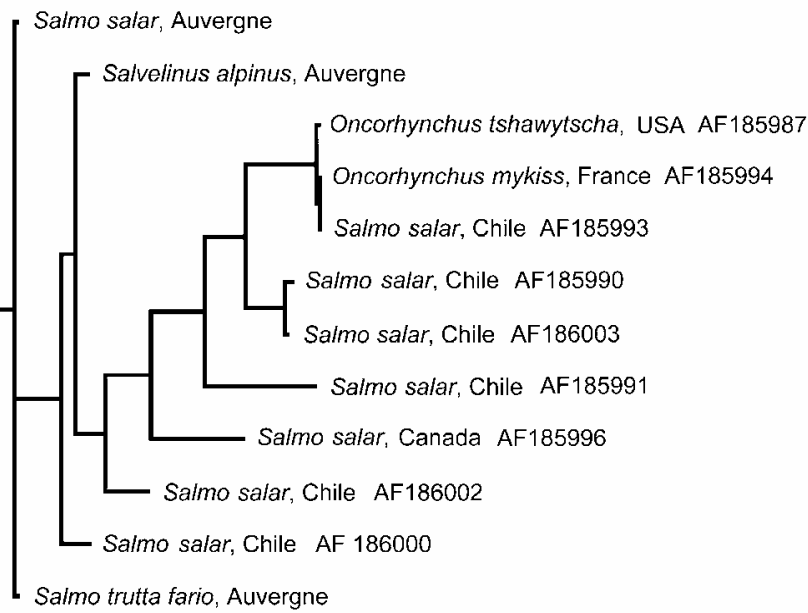

Fig. 1. Phylogenetic tree based on small subunit rDNA sequence data from Auvergne-originating and previously known Nucleospora salmonis strains.

$N$. salmonis, although they possessed heterogenous sites specific of their geographical origin (Table 2). The positions of these heterogenous sites were similar for thesequences from Auvergne isolates. When compared to the reference $N$. salmonis sequence obtained from Chinook salmon from California, USA (Gresoviac et al. 2000, GenBank acc. no. AF185987), the divergence of the Auvergne parasites was between 0.47 and $0.71 \%$ based on 849 bp of the ssu-rDNA. Although the genotyping relied on incomplete gene sequences, the comparative examination of the genotype from rainbow trout (GenBank acc. no. AF185994) collected in 1991 in rivers of Eastern France, which belong to a different water system and thus lack common effluent with the Auvergne streams investigated (S. Chilmonczyk pers. comm., Gresoviac et al. 2000), did not indicate sufficient similarities with the Massif Central samples to be grouped with these ones (Table 2, Fig. 1). In fact, the heterogeneity noted between the previously reported Eastern France $N$. salmonis isolate and the ones characterised from Auvergne was found to be similar to the divergence observed when alignment analysis was conducted using sequences from American representatives from the Pacific coast. The genetic divergence was between 0.59 and $0.71 \%$ on the basis of the rDNA sequences. When compared to previously known sequences from Atlantic salmon (AF185990, AF185991, AF185993, AF185996, AF186000, AF186002, AF186003), Auvergne-originating genotypes yielded variability ranging from 0 to $1.65 \%$. We noted that the sequences from $\mathrm{Au}$ vergne isolates of the parasite were comparable $(0$ $0.35 \%$ of divergence) to genotypes identified in Atlantic salmon from British Columbia in Canada and from Chile, with fish in both locations raised from eggs or yearlings stocks imported from the hatcheries of the East coast of Canada. However, these similarities were not observed in all $N$. salmonis samples from Atlantic salmon, included from specimens collected in common regions (e.g. Chile) (Table 2).

Similarly, alignments revealed only $0-0.24 \%$ of variability when $N$. salmonis sequences strictly from Auvergne isolates were inspected and juxtaposed to each other. On the other hand, most heterogeneous sites of the Auvergne isolates were not common among other genetically-characterised $N$. salmonis with the exception of $N$. salmonis genotypes identified in some but not all samples from identical host fish species, such as Atlantic salmon from Chile and Canada. Because we know that the N. salmonis sequences referred as AF185990, AF185991 and AF185996 were extracted from Atlantic salmon individuals from reared stocks constituted with eggs and yearlings imported from Eastern provinces of Canada, where this salmonid is autochthonous, we can fairly associate them to the ones obtained from infected Atlantic salmon in Auvergne.

Previous studies have illustrated a comparable range of sequence variability among clones produced from a single PCR reaction $(<0.25 \%$, Gresoviac et al. 2000); the resemblance between $N$. salmonis genotypes characterised in Massif Central fish and in Atlantic salmon originating from Eastern Canada was below $0.24 \%$ of variation.

\section{DISCUSSION}

This brief comparison of some typical salmonid populations representative of the Auvergne region ecosystems is the first to be conducted for the specific detection and characterisation of Nucleospora salmonis in aquaculture and streams of France. To our knowledge, it also constitutes the first attempt to identify $N$. salmonis in grayling, brown trout and charr and to link mortality and morbidity in these species to this microsporidiosis. As a consequence, we were able to clearly show that the intranuclear microsporidium is present and well disseminated among salmonids raised in local farms and by extension is probably resident to the adjacent waterways. The detection of advanced stages of the disease in juvenile as well as adult fish of several species was an indicator of the favourable and advanced development of the parasite within the examined stocks and, subsequently, the importance of the disease in Auvergne.

As noted earlier (Barlough et al. 1995) and by contrast with PCR diagnosis, the histological examination of wet mounts only allowed the detection of $N$. salmonis in moderately to severely infected tissues, but it is not conclusive. We confirmed it by PCR. The symptomatic salmon or trout extracted from the Augerolles hatchery ponds were all diagnosed with $N$. salmonis infections when inspected by PCR. In numerous cases, the progression of the parasitosis was sufficient to allow us to positively identify in most wet mounts high concentrations of characteristic spores and developmental stages of the microsporidian, within the nuclei or in the surrounding matrix of the pronephros lymphocytic cells. 
However, the samples collected from the ponds of Besse Saint Anastasie were not as consistent in demonstrating the presence of the pathogen by microscopy. It was assumed that the differences observed in the prevalence of parasitized individuals may be the result of the selection tactics of the diseased fish used by the different inspecting teams at each site or of divergent rearing methods influencing the disease expansion (Hedrick 1997). It is probable in consideration of the larger number and size of the stocks raised at Augerolles, and consequently of the resulting increased crowding and related stress in which fish are placed, that conditions were optimum for the parasite development and propagation at this site of collection. Also, it is likely that the health status of moribund fish was screened with greater care for the most affected individuals, showing every indicative signs of the microsporidiosis, among these larger fish populations, leading to a more specific selection strategy of the samples. Our study has shown that every salmonid species held in captivity in the main aquaculture establishments of the Massif Central was capable to act as host for $N$. salmonis with infections characterised by significant symptoms and death. Consequently, it appears the disease has spread to the stocks of each local representative species involved in supplementation and protection programs and already affects the health of its members, including graylings, brown trouts and charrs, but more importantly the ecologically threatened populations of 'Allier' Atlantic salmon used in restoration efforts. Furthermore, our results on the prevalence of $N$. salmonis in newly investigated species support the hypothesis that the parasite is indeed ubiquitous and distributed worldwide, in the regions frequented by salmonid fish, as suggested by earlier epidemiological work (Gresoviac et al. 2000).

We were unable to get the entire ssu-rDNA which suggests, based on previous observations (Barlough et al. 1995, Docker et al. 1997, Gresoviac et al. 2000, Khattra et al. 2000), that $N$. salmonis isolates from Auvergne may vary significatively in the ITS-bordering 3' region. Based on the analysis of their partial ssu-rDNA sequences and the resulting distance phylogenetic tree, the isolates collected in that area can be differentiated from other $N$. salmonis strains reported earlier, whether from Atlantic salmon or distinctive salmonid fish. However, complete sequencing of the ssu-rRNA gene should support the idea of a parasite genotype typical of the Massif Central-related streams which host migrating Atlantic salmon. Furthermore, the heterogeneity of sequence reported by comparison of the various parasite sequences was found to be equivalent to the variability observed during the analysis of several clones $(n=6)$ prepared from a single sample. Hence, we can hypothesize that the definition of a Loire-Allier $N$. salmonis genotype can be recognized as a single clonal unit, or riboset (Tibayrenc et al. 1991). This one is likely to be linked to representative Atlantic salmon and salmonid species found in the streams along the Northern Atlantic coastal lines and major connected river water systems since the Atlantic salmon from Europe or North America are used to be linked to common Northern Atlantic and Arctic ocean areas as part of their life cycle regardless of reproductive stream. By extension, we can also expect that this typical riboset should be found upon inspection in most salmonid populations inhabiting the river systems in which Atlantic salmon are known to spawn and run. Therefore, further investigations should be conducted in France, Northern European countries and Canada in order to verify the existence and draw the identity of a potential 'Atlantic salmon' genotype of $N$. salmonis including a subgroup associated with the presence of the 'Allier' Atlantic salmon strain.

The comparative alignment of the identified rDNA portions with the formerly classified ssu-rDNA from the isolate detected in rainbow trout by the INRA team of Jouy-en-Josas in 1991 (S. Chilmonczyk pers. comm., Gresoviac et al. 2000), is indicative of the existence of several strains, or to a lesser degree genotypes, of $N$. salmonis in France. The high proportion and specificity of the heterogeneous sequences described by the comparison of the rainbow trout isolate from Eastern France and the isolates from Massif Central salmonids, as well as the absence of common genetically-specific French sites, did not suggest any direct relationship between the microorganisms originating from these locations. We can therefore speculate the source of their respective dissemination is not found in a common French or Atlantic salmon ancestor distributed throughout the streams of France. Complementary sequencing and subsequent phylogenetic construction should tell us if this hypothesis is correct. At the same time, we were able to confirm that, as we suspected, $N$. salmonis is capable of infecting most if not all the salmonid species in a regionally specific and limited environment, in spite of variation of virulence depending of the nature of the affected host. Although we positively identified the pathogen in four distinct salmonids reared in fish farms of Auvergne, the Atlantic salmon, the grayling, the brown trout and charr, it is reasonable to assume that greater number of fish populations belonging to the salmonid group represent potential targets for $N$. salmonis or carrier host of the disease agent in Auvergne based on its propagation within that region. It appears that the parasites found in the various infected fish collected in Auvergne may have originated from a common host species, the Atlantic salmon, as demonstrated by its genetic resemblance and prevalence in North American individuals from this species which share same migration routes. The absence of reports related to other salmonid fish native or released in waterways of the Massif Central, and more generally in France, can be explained by the lack of interest or of investigative efforts conducted by the authorities concerning fish pathologies. 
As more financial and technical means are invested in the protection of the salmonids of the Massif Central rivers, further efforts should be developed to assess the risk of infectious agents, such as $N$. salmonis (Woo 1987, 1992, Hedrick 1997). Our overview of captive populations of salmons and trouts, in participation with supplementation programs, was sufficient to warn us of the threat this particular microsporidian already signifies for the local aquacultures, and consequently, for the ecological restoration and management ambitions of the region. Our results are alarming in terms of productivity and quality of fish produced for sport fishing (i.e. tourism) and river supplementation, which come in direct contact with the fisherman (i.e. consumer), or in terms of ecological preservation since infected released fish can be contaminant for natural wild populations which themselves can be more susceptible to the parasite or secondary infections due to their rare exposition to the pathogen (Wongtavatchai et al. 1995b). Increased care should be taken to contain or control the microbial agents and to monitor the development of infectious diseases in the ecosystem of the Massif Central and by relationship of the main Allier and Loire water system in France.

Acknowledgements. This work was supported by an "Environment" grant from the Regional Council of Auvergne (France) and in part by the California Department of Fish and Game, through contract no. FG-6002-IF. The authors would like to thank the Superior Council of Fishing, AuvergneLimousin regional office, and the Puy-de-Dôme Federation for Fishing and Protection of the Aquatic Habitat for their assistance. We are more particularly grateful to G. Vissac for his support in making this project possible, and H. Carmié, B. Le Chevillier and D. Gonseau for their technical contribution in the specimen collections. Special thanks to Dr. R.P. Hedrick to have accommodated Stéphane Grésoviac in his laboratory.

\section{REFERENCES}

ANTONIO D.B., HEDRICK R.P. 1995: Effect of water temperature on infections with the microsporidian Enterocytozoon salmonis in chinook salmon. Dis. Aquat. Org. 22: 233-236.

BARLOUGH J.E., McDOWELL T.S., MILANI A., BIGORNIA L., PIENIAZEK N.J., HEDRICK R.P. 1995: Nested polymerase chain reaction for detection of Enterocytozoon salmonis genomic DNA in chinook salmon Oncorhynchus tshawytscha. Dis. Aquat. Org. 23: 17-23.

BAXA-ANTONIO D., GROFF J.M., HEDRICK R.P. 1992: Experimental horizontal transmission of Enterocytozoon salmonis to chinook salmon Oncorhynchus tshawytscha. J. Protozool. 39: 699-702.

CHILMONCZYK S., COX W.T., HEDRICK R.P. 1991: Enterocytozoon salmonis $\mathrm{n}$. sp. an intranuclear microsporidium from salmonid fish. J. Protozool. 38: 264-269.

CUBILLOS V., SUAREZ D., ENRIQUEZ R., ALBERDI A., MONRAS M. 2000: Caracterización clínica y aspectos lesionales macro y microscópicos de la leucemia linfoblástica en salmones y truchas de cultivo. Arch. Med. Vet. (Valdivia) 32: 1-14.

DOCKER M.F., KENT M.L., HERVIO D.M.L., KHATTRA J.S., WEISS L.M., DEVLIN R.H. 1997: Ribosomal DNA sequence of Nucleospora salmonis Hedrick, Groff and Baxa, 1991 (Microsporea: Enterocytozoonidae): implications for phylogeny and nomenclature. J. Eukaryot. Microbiol. 44: 55-60.

EATON W.D., FOLKINS B., KENT M.L. 1994: Biochemical and histologic evidence of plasmacytoid leukemia and salmon leukemia virus (SLV) in wild-caught chinook salmon Oncorhynchus tshawytscha from British Columbia expressing plasmacytoid leukemia. Dis. Aquat. Org. 19: $147-151$.

EATON W.D., KENT M.L. 1992: A retrovirus in chinook salmon (Oncorhynchus tshawytscha) with plasmacytoid leukemia and evidence for the etiology of the disease. Cancer Res. 52: 6496-6500.
ELTSON R.A., KENT M.L., HARRELL L.H. 1987: An intranuclear microsporidium associated with an acute anaemia in the chinook salmon. J. Protozool. 34: 274-277.

GEORGIADIS M.P., GARDNER I.A., HEDRICK R.P. 1998: Field evaluations of sensitivity and specificity of a polymerase chain reaction (PCR) for detection of Nucleospora salmonis in rainbow trout. J. Aquat. Anim. Health 10: 372-380.

GRESOVIAC S.J., KHATTRA J.S., NADLER S.A., KENT M.L., DEVLIN R.H., VIVARES C.P., de la FUENTE E., HEDRICK R.P. 2000: Comparison of small subunit ribosomal RNA gene and internal transcribed spacer region sequences among isolates of the intranuclear microsporidian Nucleospora salmonis. J. Eukaryot. Microbiol. 47: 379-387.

HEDRICK R.P. 1997: How microbial diseases of salmonids impact aquaculture. Austr. Microbiol. 18: 26-30.

HEDRICK R.P., GROFF J.M., BAXA D. 1991: Experimental transmission and progress of Enterocytozoon salmonis infections in chinook salmon (Oncorhynchus tshawytscha). Dis. Aquat. Org. 10: 103-108.

HEDRICK R.P., GROFF J.M., McDOWELL T.S., WILLIS M., COX W.T. 1990: Hematopoietic intranuclear microsporidian infections with features of leukemia in chinook salmon Oncorhynchus tshawytscha. Dis. Aquat. Org. 8: 189-197.

KENT M.L., GROFF J.M., TRAXLER G.S., ZINKL J.G., BAGSHAW J.W. 1990: Plasmacytoid leukemia in seawater reared chinook salmon, Oncorhynchus tshawytscha. Dis. Aquat. Org. 8: 199-209.

KENT M.L., HERVIO D.M.L., DOCKER M.F., DEVLIN R.H. 1996: Taxonomy studies and diagnostic tests for myxosporean and microsporidian pathogens of salmonid fishes utilizing ribosomal DNA sequence. J. Eukaryot. Microbiol. 43: S98-99.

KENT M.L., RANTIS V., BAGSHAW J.W., DAWE S.C. 1995: Enhanced detection of Enterocytozoon salmonis (Microspora), an intranuclear microsporean of salmonid 
fishes, with the Warthin-Starry stain combined with hematoxylin and eosin. Dis. Aquat. Org. 23: 235-237.

KHATTRA J.S., KENT M.L., GRESOVIAC S.G., MYERS M.S., HEDRICK R.P., DEVLIN R.H. 2000: Molecular detection and phylogenetic placement of a microsporidium from English sole (Pleuronectes vetulus) affected by Xcell pseudotumors. J. Parasitol. 86: 867-871.

LOM J. 2002: A catalogue of described genera and species of microsporidians parasitic in fish. Syst. Parasitol. 53: 8199.

LOM J., NILSEN F. 2003: Fish microsporidia: fine structural diversity and phylogeny. Int. J. Parasitol. 33: 107-127.

MacCONNELL E., SHAW T., SMITH C.E. 1991: Naturallyoccurring infection with intranuclear microsporidium Enterocytozoon salmonis in steelhead trout Oncorhynchus mykiss. Proc. 4th Annual AFS/FHS Meeting, 32nd Western Fish Disease Conference, Newport, Oregon, USA, 31 July-3 August 1991, p. 11.

MODIN J.C. 1981: Microsporidium rhabdophilia n. sp. from the rodlet cells of salmonid fishes. J. Fish Dis. 4: 203-211.

MORRISON J.K., MacCONNELL E., CHAPMAN P.F., WESTGARD R.L. 1990: A microsporidium induced lymphoblastosis in chinook salmon (Oncorhynchus tshawytscha) in fresh water. Dis. Aquat. Org. 8: 99-104.
MULLINS J.E., POWELL M., SPEARE D.J., CAWTHORN R. 1994: An intranuclear microsporidian in lumpfish Cyclopterus lumpus. Dis. Aquat. Org. 20: 7-13.

NILSEN F., NESS A., NYLUND A. 1995: Observations on an intranuclear microsporidium in lymphoblasts from farmed Atlantic halibut larvae (Hippoglossus hippoglossus L.). J. Eukaryot. Microbiol. 42: 131-135.

TIBAYRENC M., KJELLBERG F., AYALA F.J. 1991: The clonal theory of parasitic protozoa. Bioscience 41: 767774.

WONGTAVATCHAI J., CONRAD P.A., HEDRICK R.P. 1995a: In vitro characteristics of the microsporidian $E n$ terocytozoon salmonis. J. Eukaryot. Microbiol. 42: 401405.

WONGTAVATCHAI J., CONRAD P.A., HEDRICK R.P. 1995b: Effect of the microsporidian Enterocytozoon salmonis on the immune response of chinook salmon. Vet. Immunol. Immunopathol. 48: 367-374.

WOO P.T.K. 1987: Immune response of fish to parasitic protozoa. Parasitol. Today 3: 186-188.

WOO P.T.K. 1992: Immunological responses in fish to parasitic organisms. Annu. Rev. Fish Dis. 2: 339-366. 